\title{
Recrystallization Kinetics of Low and Ultra Low Carbon Steels during High-rate Annealing
}

\author{
M. FERRY, D. MULJONO"1) and D. P. DUNNE' \\ School of Materials Science and Engineering, University of New South Wales, Sydney NSW 2052, Australia. \\ E-mail: m.ferry@unsw.edu.au 1) Research and Development Centre, Pt Krakatau Steel, Indonesia. \\ 2) Faculty of Engineering, University of Wollongong, Wollongong NSW 2522, Australia.
}

(Received on April 11, 2001; accepted in final form on June 6, 2001)

\begin{abstract}
Annealing experiments were carried out to study the effect of rapid heating rates on the recrystallization kinetics and grain size of steels with a range of carbon levels $(0.003-0.05 \% \mathrm{C})$. The steels were cold-rolled to $70 \%$ reduction and subsequently annealed at heating rates from 50 to $1000^{\circ} \mathrm{C} / \mathrm{s}$ to peak temperatures $\left(T_{p}\right)$ in the range 600 to $800^{\circ} \mathrm{C}$ and held at $T_{p}$ for various times and cooled to ambient temperature at a rates up to $2000^{\circ} \mathrm{C} / \mathrm{s}$. For the steels investigated, the rate of anisothermal recrystallization and the final grain size decreases with increasing heating rate. These results do not support previous work in which it was concluded that ultra-rapid softening (which was associated with an observed decrease in recrystallization temperature at high heating rate and a concomitant increase in grain size) occurs at heating rates in excess of $500^{\circ} \mathrm{C} / \mathrm{s}$. An annealing model, based on JMAK transformation kinetics, is presented, which predicts the kinetics of recrystallization for any combination of input parameters: heating rate, peak temperature, holding time and cooling rate. The model is shown to predict the strong effect of holding time and cooling rate on the rate of recrystallization at high heating rates.
\end{abstract}

KEY WORDS: recrystallization; grain size; continuous annealing; JMAK equation; steel.

\section{Introduction}

Two important commercial processes for annealing coldrolled steel are batch annealing (BA) and continuous annealing (CA). Continuous annealing is becoming the preferred method as it has many advantages over batch annealing such as a short processing time as well as producing strip with excellent flatness and more uniform mechanical properties. ${ }^{1)}$ A current limitation of CA arises from the line speed being limited by heat transfer through the sheet surface. As a consequence, the maximum heating rate achievable in conventional CA lines using radiant or convective heating is about $100^{\circ} \mathrm{C} / \mathrm{s}$. Therefore, the process requires a relatively long annealing line and productivity is limited. In an effort to overcome this heating rate deficiency, faster processing methods have been proposed. One such method is transverse flux induction heating $(\mathrm{TFIH})^{2)}$ which may offer advantages over the more conventional annealing processes by reducing annealing time, allowing a more compact annealing line and providing greater control of microstructure and properties. As the TFIH process is capable of continuous annealing steel strip at heating rates up to $1000^{\circ} \mathrm{C} / \mathrm{s}$, it is important to understand the effect of rapid heating rates on the recrystallization behaviour of cold rolled steel strip. This is important as it has been argued that annealing of low carbon steel at high heating rates $\left(>500^{\circ} \mathrm{C} / \mathrm{s}\right)$ may result in accelerated softening. ${ }^{3-5)}$ Such terminology was used to explain a discontinuous change in annealing behaviour, that is, a sharp depression of the recrystallization start temperature and an increase in the rate of recrystallization above a critical heating rate. For a range of low carbon steels, it was reported that a high-rate annealing results in complete recrystallization in a fraction of a second over a small temperature range, producing a coarsegrained microstructure with a strong recrystallization texture, that is, sharpening of the favourable $\{111\} /$ ND (normal direction) texture components or $\gamma$-fibre. ${ }^{3)}$

Numerous models have been proposed for predicting the kinetics of isothermal recrystallization in cold deformed metals. ${ }^{6)}$ These are often based on Johnson-Mehl-AvramiKolmogorov (JMAK) transformation kinetics, ${ }^{7-11)}$ microstructural path methodology ${ }^{12-14)}$ or computer simulation. ${ }^{15)}$ Humphreys and Hatherly have recently reviewed various models, together with their applicability to studies of recrystallization kinetics in deformed metals. ${ }^{6}$ ) It was shown that a very useful equation for predicting recrystallization kinetics in a wide range of materials is the generalised form of the JMAK equation:

$$
X_{\mathrm{v}}\left(T_{\mathrm{i}}\right)=1-\exp \left\{-k(T) t^{n}\right\}
$$

where $X_{\mathrm{v}}\left(T_{\mathrm{i}}\right)$ is the volume fraction transformed at a temperature $T_{\mathrm{i}}, t$ is time, $n$ is the Avrami (or JMAK) exponent and $k\left(T_{\mathrm{i}}\right)$ is a term incorporating both the nucleation and growth rate of grains.

In continuous annealing of cold rolled steel strip, recrystallization will occur anisothermally during heating to the 
required temperature. ${ }^{16)}$ In particular, continuous annealing processes usually involve high heating rates $\left(>10^{\circ} \mathrm{C} / \mathrm{s}\right)$ to a set temperature followed by either a short soaking period or direct cooling. ${ }^{17)}$ Models based on Eq. (1) have been developed to predict the recrystallization kinetics of a range of metals during the heating stage of a continuous annealing cycle. ${ }^{18-20)}$ During rapid annealing of metals, however, recrystallization commences during heating but restriction of the peak temperature results in incomplete recrystallization, and the fully recrystallized state is only achieved during the isothermal holding and cooling stages. ${ }^{16)}$ In this case, it is necessary to accommodate the anisothermal component/s of the annealing cycle with isothermal holding stages.

The objective of the present work is to study the effect of heating rate (up to $1000^{\circ} \mathrm{C} / \mathrm{s}$ ) on the recrystallization kinetics of cold rolled steels with carbon contents in the range 0.003 to $0.05 \mathrm{wt} \% \mathrm{C}$ and to determine if accelerated softening occurs beyond a critical heating rate in these steels. ${ }^{3)}$ The work also describes a simple annealing model to predict the fraction recrystallized during a continuous annealing cycle and accounts for any number of anisothermal and isothermal components of the cycle, which is necessary for metals that either undergo complex thermal treatments or when rapid heating rates are required. This model is extended to predict the effect of isothermal holding and cooling rate on the progress of recrystallization during rapid heating and to determine if the earlier results of ultra rapid softening can be predicted.

\section{Experimental}

\subsection{Materials and Annealing Method}

Steels with carbon contents 0.003, 0.02 and $0.05 \mathrm{wt} \%$ were supplied by BHP Steel, Port Kembla in the hot rolled condition. The steel designation, composition and initial grain size are given in Table 1. As-hot-rolled samples were cold rolled to $70 \%$ reduction and $10 \mathrm{~mm} \times 40 \mathrm{~mm}$ strips were cut with the longer dimension parallel to the rolling direction (RD). The samples were annealed by resistance heating using a Gleeble 3500 thermal and mechanical simulator. This facility is capable of simulating continuous annealing, whereby a steel sample can be heated at a constant rate to a given temperature followed either by (i) immediate cooling at a specified rate, or (ii) holding isothermally before cooling. For accurate temperature control during annealing, a $0.13 \mathrm{~mm}$ diameter type $\mathrm{K}$ thermocouple was spot welded to each specimen.

Specimens were annealed at heating rates from 50 to $1000^{\circ} \mathrm{C} / \mathrm{s}$ to a peak temperature, $T_{\mathrm{p}}$, ranging from 600 to

Table 1. Samples for recrystallization studies in Gleeble 3500 simulator showing, for each steel, alloy designation, initial ferrite grain size and composition.

\begin{tabular}{|c|c|c|c|c|c|c|}
\hline \multirow{2}{*}{$\begin{array}{c}\text { Steel designation and initial } \\
\text { ferrite grain size }(\mu \mathrm{m})\end{array}$} & \multicolumn{5}{|c|}{ Composition (wt.\%) } \\
\cline { 2 - 6 } \multicolumn{2}{|c|}{} & $\mathrm{C}$ & $\mathrm{Mn}$ & $\mathrm{Ti}$ & $\mathrm{Al}$ & $\mathrm{N}$ \\
\hline $\mathbf{1}$ & 20 & 0.05 & 0.34 & 0.005 & 0.03 & 0.005 \\
\cline { 1 - 2 } $\mathbf{2}$ & 20 & 0.02 & 0.32 & 0.005 & 0.04 & 0.005 \\
\cline { 1 - 2 } & 30 & 0.003 & 0.19 & 0.004 & 0.03 & 0.003 \\
\hline
\end{tabular}

$800^{\circ} \mathrm{C}$ followed by isothermal holding and cooling at a given rate. To study the effect of heating rate on anisothermal recrystallization and to minimise masking effects associated with rapid isothermal recrystallization at high temperature, samples were water-quenched within $0.05 \mathrm{~s}$ of reaching $T_{\mathrm{p}}$

\subsection{Microstructural Analysis}

The annealing procedure outlined in Sec. 2.1 produces small volumes of material within $2^{\circ} \mathrm{C}$ of the required peak temperature, ${ }^{21)}$ and these are ideal for microstructural analysis. The microstructural development of the cold rolled and annealed samples were examined by optical microscopy following polishing and etching in a $2 \%$ nital solution. The volume fraction recrystallized and final grain size for each sample were determined using standard ASTM quantitative metallographic techniques, ${ }^{21)}$ by averaging measurements taken along the RD direction at $1 / 4$, $1 / 2$ and 3/4 thickness of ND-RD sections of the sheet. The average grain size was determined by the linear intercept method and volume fraction recrystallized was determined by point counting using a $10 \times 10$ grid at a magnification of $200 \times$ on 30 random areas of the microstructure.

\section{Results and Discussion}

\subsection{Recrystallization Behaviour during Rapid An- nealing}

The effect of heating rate on the recrystallization kinetics of the steels are given in Fig. 1, where it can be seen that an increase in heating rate raises both the nucleation temperature $\left(T_{\mathrm{N}}\right)$ and temperature to complete recrystallization $\left(T_{\mathrm{f}}\right)$. To represent more clearly the progress of recrystallization, the temperature for $50 \%$ recrystallization $\left(T_{0.5}\right)$ was used. Figure 2(a) is a plot of $T_{0.5}$ as a function of heating rate which shows that increasing heating rate raises $T_{0.5}$. Similar behaviour was observed for the temperatures for $10 \%\left(T_{0.1}\right)$ and $90 \%\left(T_{0.9}\right)$ recrystallization (Fig. $\left.2(\mathrm{~b})\right)$ which are useful approximations of $T_{\mathrm{N}}$ and $T_{\mathrm{f}}$. With increasing heating rate, a decrease in the mean grain size just after the completion of recrystallization was observed for all steels (Fig. 3). Such grain refinement is in agreement with previous lower heating rate work ${ }^{22)}$ where it was argued that an increased heating rate raises the nucleation temperature (see e.g. Fig. 2(b)) due to the finite time required to produce viable nuclei, ${ }^{6}$ and hence, increase the nucleation rate as $\dot{N} \propto$ $\exp \left(-Q_{\mathrm{N}} / R T\right)$ where $Q_{\mathrm{N}}$ is the activation energy for nucleation.

The present study shows, for steels with a wide range of carbon levels $(0.003-0.05 \% \mathrm{C})$, that an increase in heating rate results in an increase in the recrystallization start temperature and temperature range of recrystallization, and a decrease in the final grain size. It was reported recently ${ }^{3,4)}$ that a different type of annealing phenomenon termed ultrarapid softening (which is associated with an observed decrease in recrystallization temperature at high heating rate) may occur in some low carbon steels at rates in excess of $\sim 500^{\circ} \mathrm{C} / \mathrm{s}$. It was claimed that beyond a critical heating rate, recrystallization is accelerated, and a coarse recrystallized grain size is produced. In light of these observations, and from limited TEM studies ${ }^{3,4)}$ it was argued that rapid 

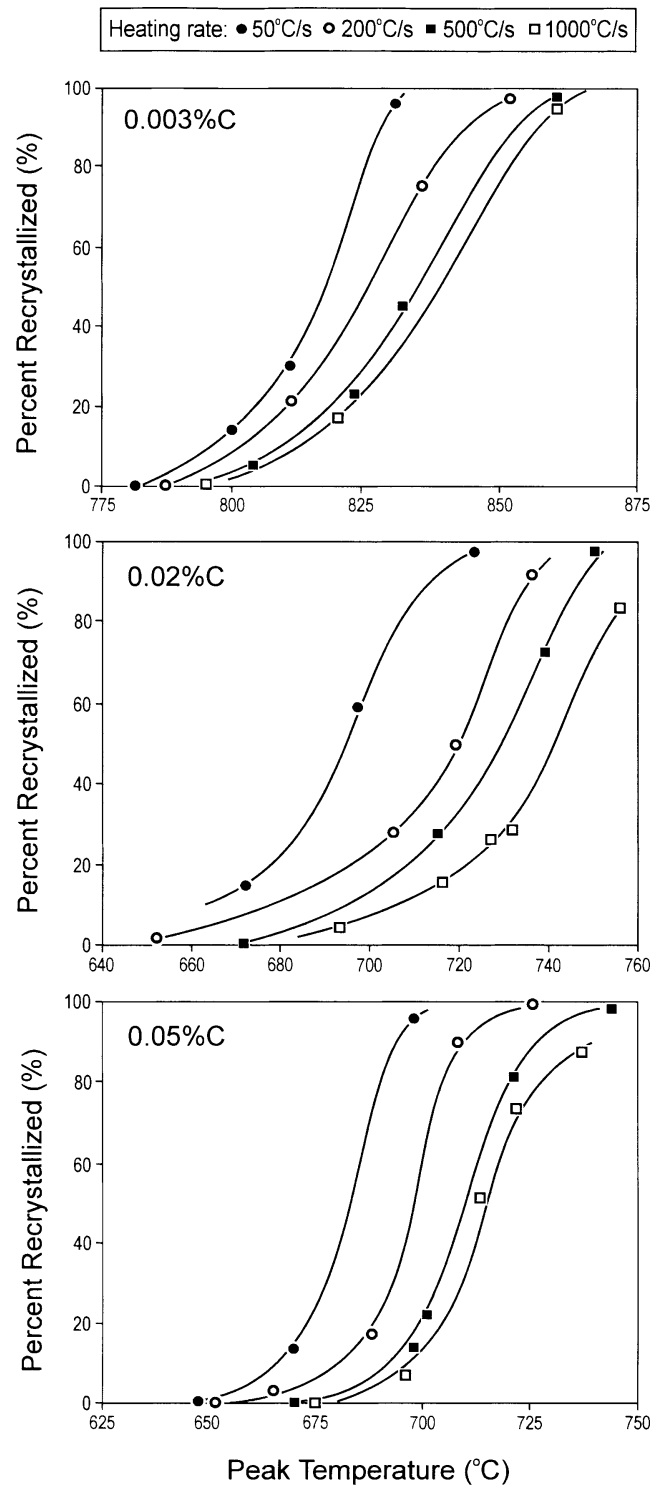

Fig. 1. Fraction recrystallized as a function of peak temperature, $T_{\mathrm{p}}$, for steels $1-3$ cold rolled to $70 \%$ reduction and heated at rates from $50^{\circ} \mathrm{C} / \mathrm{s}$ to $1000^{\circ} \mathrm{C} / \mathrm{s}$ to $T_{\mathrm{p}}$.

heating enables rapid annihilation of statistically stored dislocations rather than relaxation of the substructure into more stable arrays (i.e. polygonization). It was further argued that this bifurcation of recovery processes allows easy nucleation with the associated high angle boundaries advancing rapidly into simple dislocation arrays. ${ }^{4)}$ In contrast to the previous work, the present study shows that a discontinuous change in annealing behaviour does not occur at heating rates up to $1000^{\circ} \mathrm{C} / \mathrm{s}$ for steels containing a range of carbon levels.

\subsection{The Occurrence of 'Ultra-rapid Softening'}

Detailed experiments were recently carried out to clarify the effect of overshooting of the peak temperature $T_{\mathrm{p}}$ on recrystallization during high-rate annealing. ${ }^{21)}$ It was shown that extreme care must be taken to minimise overshooting at high heating rates $\left(>500^{\circ} \mathrm{C} / \mathrm{s}\right)$ which is controlled by the sensitivity of the thermocouple and the speed of the quench. Given that a typical thermocouple has a $10 \mathrm{~ms}$ response time, this corresponds to a maximum accuracy in
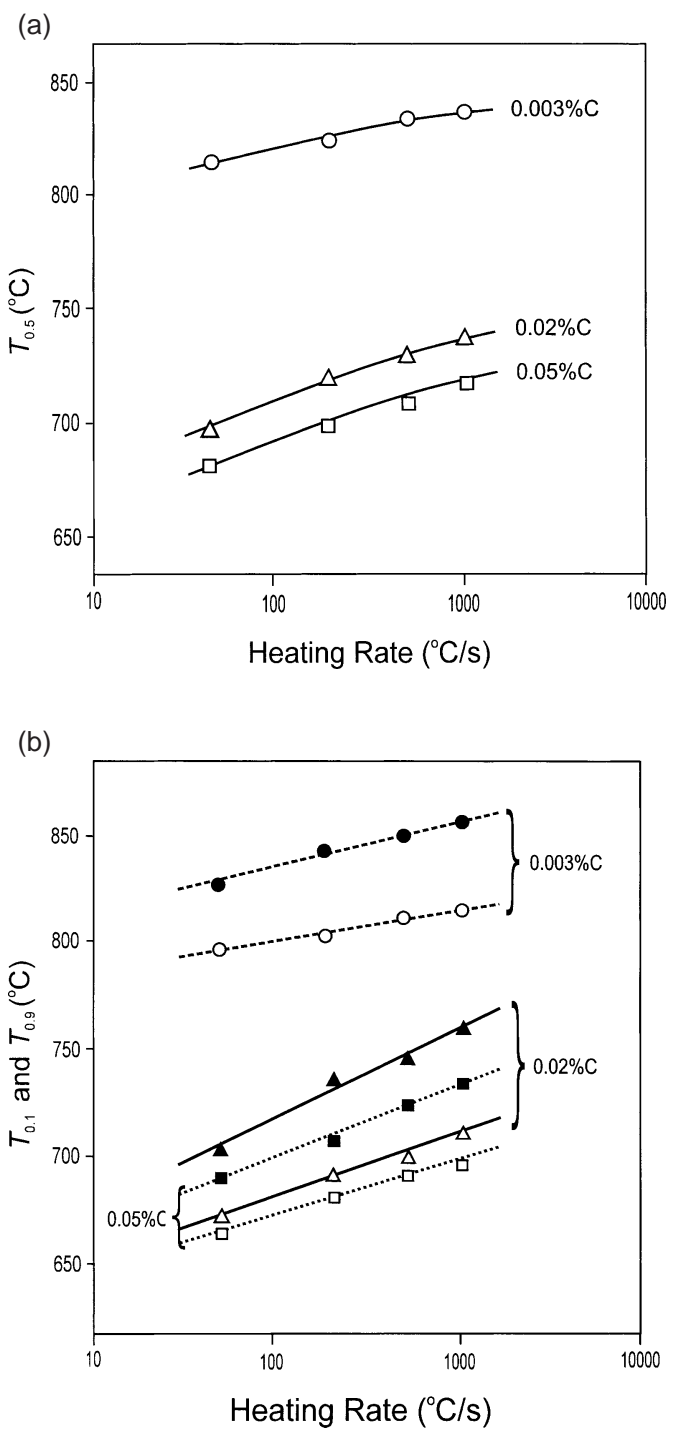

Fig. 2. Effect of heating rate on (a) the temperature to complete $50 \%$ recrystallization $\left(T_{0.5}\right)$ and (b) the temperatures to start recrystallization $\left(T_{0.1}\right)$ (open symbols) and complete recrystallization $\left(T_{0.9}\right)$ (filled symbols) for steels $1-3$.

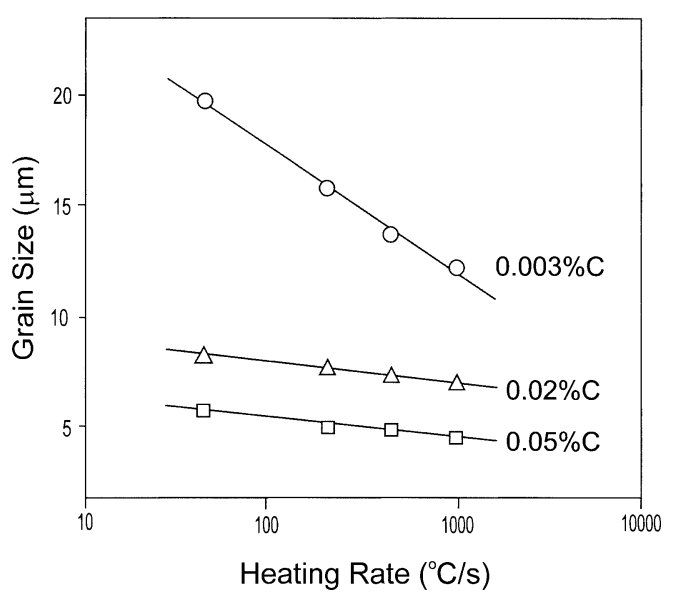

Fig. 3. Effect of heating rate on recrystallized grain size in steels $1-3$.

temperature measurement of $\pm 5^{\circ} \mathrm{C}$ at a heating rate of $500^{\circ} \mathrm{C} / \mathrm{s}$ and a greater inaccuracy at higher rates. Temperature overshoot, if not controlled, can result in enhanced 


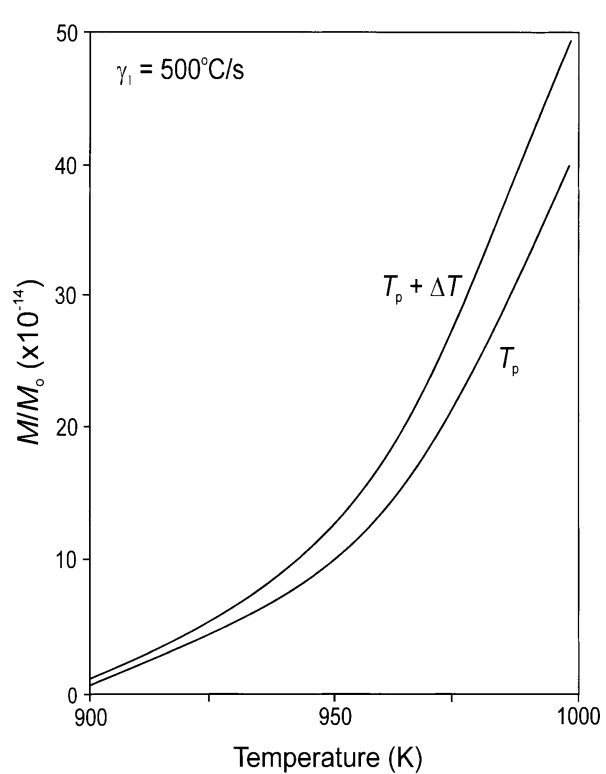

Fig. 4. Influence of temperature on grain boundary mobility illustrating the effect of a $10 \mathrm{~ms}$ thermocouple response time on mobility at $T_{\mathrm{p}}^{\prime}$ (Heating rate, $\gamma_{1}=500^{\circ} \mathrm{C} / \mathrm{s}$ ).

recrystallization and will give, at high heating rates, the impression that the recrystallization temperature is depressed. ${ }^{21)}$ This is the direct result of the thermally-activated nature of both nucleation rate and grain boundary mobility. ${ }^{6}$ For example, the mobility of a recrystallizing grain boundary may be given as:

$$
M=M_{\mathrm{o}} \exp \left(-Q_{\mathrm{g}} / R T\right)
$$

where, $T$ is the absolute annealing temperature, $Q_{\mathrm{g}}$ is the activation energy for boundary migration and $M_{\mathrm{o}}$ is a preexponential constant. If we take the uncertainty of measuring $T_{\mathrm{p}}$ due to the response time of the thermocouple to be $\Delta T$ we have at the peak temperature:

$$
M=M_{\mathrm{o}} \exp \left(-Q_{\mathrm{g}} / R\left(T_{\mathrm{p}}+\Delta T\right)\right)
$$

Taking $Q_{\mathrm{g}}$ for iron to be $327 \mathrm{k} / \mathrm{mol},{ }^{21)}$ Eq. (3) is plotted as $M / M_{\mathrm{o}}$ as a function of $T_{\mathrm{p}}$ taking into account a peak overshoot of $5^{\circ} \mathrm{C}$ for a heating rate of $500^{\circ} \mathrm{C} / \mathrm{s}$ (Fig. 4). This figure shows the influence of overshoot on grain boundary mobility, and illustrates the importance of careful temperature measurement on recrystallization.

With reference to Fig. 4 it is clear that if high heating rates produce moderate overshooting, this will result in rapid boundary migration to full recrystallization and, possibly, further grain growth (particularly if quenching is not facilitated immediately on reaching $T_{\mathrm{p}}$ ) leading to a coarser final grain size, which is contrary to the present observations (Fig. 3). Grain growth in low carbon steel is known to strengthen the $\{111\} / / \mathrm{ND}$ texture components ${ }^{22,23)}$ and this may contribute to the previous observations ${ }^{3)}$ of texture sharpening at high heating rates. In the present steels, a strengthening of the $\gamma$-fibre was observed with increasing heating rate up to $200^{\circ} \mathrm{C} / \mathrm{s}^{16)}$ but this was attributed to additional grain boundary nucleation, a factor which also decreases the recrystallized grain size.

It has been demonstrated ${ }^{21)}$ that annealing variables such as isothermal holding time and the rate of cooling from $T_{\mathrm{p}}$ also influence the fraction recrystallized during rapid heat-

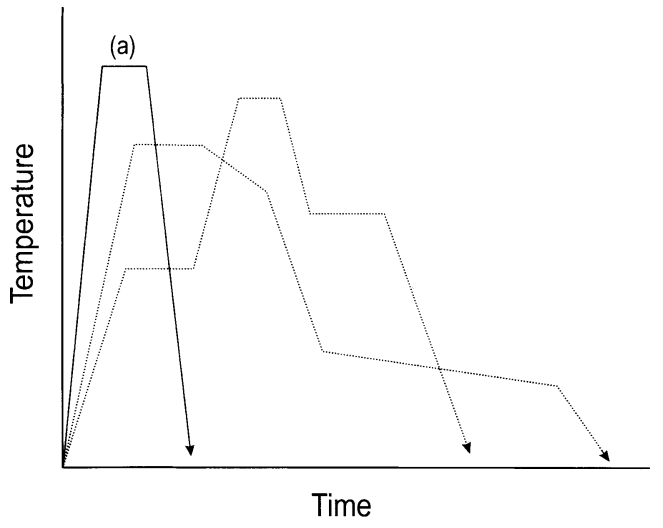

Fig. 5. Schematic diagram of some potential annealing cycles following cold deformation.

ing. The effect of these variables on the fraction recrystallized as a function of heating rate will now be demonstrated using a simple annealing model.

\subsection{Recrystallization Model for a Multi-stage An- nealing Cycle}

To predict satisfactorily the progress of recrystallization during high-rate continuous annealing, any model must take into account the various heating and cooling stages, together with the isothermal holding stages (see e.g. Fig. 5). The model must include the following aspects of the process:

(i) during heating at a given rate $\left(\gamma_{1}\right)$, recrystallization starts at a temperature $T_{0}$ and proceeds anisothermally to a temperature $T_{1}$;

(ii) if recrystallization is incomplete at $T_{1}$, it will proceed either isothermally in a given time interval $\Delta t$, or during further heating at a different rate $\left(\gamma_{2}\right)$ to a temperature $T_{2}$ (thus recrystallization may proceed through any combination of heating and holding stages);

(iii) if recrystallization is incomplete after the steps outlined in (ii), further recrystallization will occur during subsequent cooling.

While recrystallization during continuous annealing may involve any number of anisothermal and isothermal components, it is possible to predict the recrystallization kinetics based on JMAK transformation kinetics (Eq. (1)) if certain assumptions can be satisfied:

- isothermal recrystallization follows Eq. (1);

- the rule of additivity ${ }^{24)}$ applies;

- nucleation is site saturated such that nucleation takes place at the start of recrystallization and the rate is zero thereafter; ${ }^{25)}$

- the JMAK constant, $n$, is constant over the temperature range where recrystallization occurs, ${ }^{26)}$ and

- the growth rate of nucleated grains is thermally activated and, for a given temperature, is constant with time.

Before outlining the model (Appendix A), it is useful to test the validity of these assumptions, based on the available experimental data of cold deformed and annealed steels. Equation (1) is a key element in the model but there are some restrictions in its use to model recrystallization, and deviation of experimental data from the model is well-documented. ${ }^{6}$ Nevertheless, due to the simplicity of Eq. (1), it has been used extensively to predict recrystallization in a 
wide range of alloys, and is regarded as a satisfactory relation for predicting isothermal transformation kinetics in materials. $^{6}$ )

To predict the progress of recrystallization during the anisothermal stage of an annealing cycle, the rule of additivity, proposed initially by Scheil, ${ }^{24)}$ must be satisfied. Using this rule, the start of recrystallization under anisothermal annealing conditions can be predicted if the time spent at a particular temperature, $t_{i}$, divided by the incubation time, $\tau_{i}$, is considered to be representative of the fraction of the total nucleation time required. ${ }^{24)}$ Scheil proposed that a phase transformation (or recrystallization) begins when the sum of such fractions (called the fractional nucleation time) reaches unity:

$$
\sum_{i=1}^{n} \frac{t_{i}}{\tau_{i}}=1 \quad \text { or } \quad \int_{t_{0}}^{t} \frac{d t}{\tau_{x}(T)}=1
$$

The additivity rule can be extended to include the whole range of transformed fraction (i.e. from 0 to 1 ). The rule may be stated as follows: ${ }^{26)}$ given an isothermal diagram for time $\tau_{x}(T)$ as a function of temperature, at which the reaction has reached a fractional completion, $X_{\mathrm{v}}$, then the fractional completion on continuous heating will be $X_{\mathrm{v}}$ when the integral in Eq. (4) reaches unity:

$$
\int_{t_{0}}^{t} \frac{d t}{\tau_{x}(T)}=\int_{T_{0}}^{T} \frac{1}{\tau_{x}(T)} \frac{d t}{d T} d T=1
$$

Avrami ${ }^{9)}$ suggested that the transformed fraction will be additive, over a given temperature range, if the rate of nucleation is proportional to the rate of growth over that range. Such a reaction was termed isokinetic. Cahn ${ }^{25)}$ subsequently argued that a reaction is general isokinetic if the reaction rate depends on $X_{\mathrm{v}}$ and $T$ and not on the thermal path by which it reached that state, i.e:

$$
\frac{d X_{\mathrm{v}}}{d t}=f\left(X_{\mathrm{v}}\right) \cdot g(T)
$$

Cahn further proposed that if the nucleation sites are activated early in the reaction (i.e. site saturated), and if the growth rate at any instant depends only on temperature, the transformed fraction will be additive. Equation (6) therefore allows a wide range of anisothermal reactions, such as recrystallization during continuous annealing, to be predicted from isothermal kinetics data using the rule of additivity. A critical appraisal of the rule of additivity was published recently by Lusk and Jou ${ }^{27)}$ where it was shown that the rule must be applied with caution. For example, the JMAK exponent must be constant over the temperature range where transformation (recrystallization) occurs. Both site saturated nucleation and a temperature-invariant JMAK exponent have been found during recrystallization of low carbon steels ${ }^{14)}$ and implies that the present model should be applicable to continuous annealing of these materials. The final assumption of a constant isothermal growth rate of grains is necessary to simplify the overall analysis. While a constant isothermal growth rate of grains is rarely observed, ${ }^{6}$ the small decrease in growth rate with time during isothermal annealing will be largely offset by the strong temperature dependence of this parameter.

The analysis outlined in Appendix A produces the following equation which takes into account the effect of any number $(k)$ of anisothermal and isothermal annealing stages (as depicted in Fig. 5) on the fraction recrystallized during annealing:

$$
\begin{aligned}
X_{\mathrm{v}}= & 1-\exp \left(-\left[\sum _ { i = 1 } ^ { k } \left\{\int_{T_{i-1}}^{T_{i}} \frac{k(T)^{1 / n}}{\gamma_{i}} d T\right.\right.\right. \\
& \left.\left.\left.+\left(\int k(T)^{1 / n} d t\right)_{T_{i}}\right\}\right]^{n}\right)
\end{aligned}
$$

Equation (7) is the generalised form of that given by Hutchinson and Ushioda. ${ }^{18)}$

\subsubsection{High-rate Continuous Annealing of Steel}

For a simple heating, holding and cooling cycle (cycle (a) in Fig. 5), Eq. (7) reduces to:

$$
\begin{aligned}
X_{\mathrm{v}}=1-\exp \left[-\left\{\int_{T_{0}}^{T_{1}} \frac{k(T)^{1 / n}}{\gamma_{1}} d T\right.\right. & \overbrace{\text { heating }}^{\frac{k}{\gamma_{2}}} d T\}^{n}] \ldots \ldots \ldots(8) \\
& +\left(\int k(T)^{1 / n} d t\right)_{T_{i}}^{T_{T_{2}}}+\overbrace{\text { cooling }}^{\frac{k(T)^{1 / n}}{\gamma_{2}}}
\end{aligned}
$$

Assuming $\left.k(T)=A \exp (Q / R T),{ }^{6}\right)$ where $A$ is a pre-exponential factor which incorporates both the nucleation and growth rates of grains and $Q$ is an apparent activation energy term (not necessarily the same as $Q_{\mathrm{g}}$ in Eq. (2)), the fraction recrystallized may be given as:

$$
\begin{aligned}
X_{\mathrm{v}}= & 1-\exp \left[-A\left\{\int_{T_{0}}^{T_{1}} \frac{(\exp (-Q / R T))^{1 / n}}{\gamma_{1}} d T\right.\right. \\
& \left.+\left(\exp \left(Q / R T_{1}\right)^{1 / n} \Delta t+\int_{T_{1}}^{T_{2}} \frac{(\exp (-Q / R T))^{1 / n}}{\gamma_{2}} d T\right\}^{n}\right]
\end{aligned}
$$

where $\gamma_{1}$ and $\gamma_{2}$ are the heating and cooling rates respectively $(\mathrm{K} / \mathrm{s}), T_{0}, T_{1}, T_{2}$ are the start, peak and finish temperatures for recrystallization $(K)$, and $\Delta t$ is the isothermal holding time at $T_{1}(\mathrm{~s})$.

Equation (9) can be used to predict the recrystallization kinetics during continuous annealing, given that the parameters $T_{0}, T_{2}, A, Q$ and $n$ are known for a particular alloy. The variables $T_{1}, \gamma_{1}$ and $\gamma_{2}$ are input data in the model.

\subsubsection{Comparison of Model with Experiment}

To test the validity of the model, high-rate annealing ex- 
periments were conducted on the cold rolled $0.05 \mathrm{wt} \% \mathrm{C}$ steel. To produce the desired starting microstructure, ${ }^{21)}$ ashot rolled samples were: (i) cold rolled $\sim 20 \%$ reduction; (ii) samples were encapsulated in argon-flushed silica tubes and annealed at $710^{\circ} \mathrm{C}$ for $12 \mathrm{~h}$ to produce an equiaxed grain size of $100 \mu \mathrm{m}$, and (iii) samples were furnace cooled at $5^{\circ} \mathrm{C} / \mathrm{h}$ to room temperature to produce an ultra low carbon matrix. Following cold rolling to $70 \%$ reduction, specimens were annealed at heating rates of 50 to $1000^{\circ} \mathrm{C} / \mathrm{s}$ to a peak temperature ranging from 600 to $800^{\circ} \mathrm{C}$ with holding times from 0 to 20 s followed by cooling at rates up to $500^{\circ} \mathrm{C} / \mathrm{s}$

To determine $n, Q$ and $A$ in Eq. (9), it was necessary to determine the volume fraction recrystallized $\left(X_{\mathrm{v}}\right)$ as a function of annealing time $(1,3,7,10$ and $20 \mathrm{~s})$ at temperatures of 650,680 and $700^{\circ} \mathrm{C}$ for a range of heating rate $(50,500$ and $\left.1000^{\circ} \mathrm{C} / \mathrm{s}\right)$. The isothermal kinetic parameters resulting from this analysis were $n=1.003, Q=171.6 \mathrm{~kJ} / \mathrm{mol}$ and $A=4.1 \times 10^{8} \mathrm{~s}^{-1}$. ${ }^{21)}$ The average value of $n$ is close to unity, which has been found in other alloy systems, ${ }^{6)}$ and implies that nucleation dominates the recrystallization process (as required in the model). ${ }^{19)}$ In the present work, the appropriate $k(T)$ values were recalculated at each test temperature to determine the isothermal recrystallization kinetics. Using these experimentally-obtained kinetic parameters, the fraction recrystallized during anisothermal recrystallization was calculated using a computer algorithm to solve the integrals in Eq. (9). Figure 6 shows the comparison between measured values of fraction recrystallized and those predicted by the model which shows a good correlation over a wide range of annealing conditions (heating rate, holding time and cooling rate), and indicates that the model is useful for predicting trends during high-rate annealing of low and ultra low carbon steels.

\subsubsection{Influence of Processing Parameters on Recrystal- lization}

Using the data given Sec. 3.3.2 for the low carbon steel, the effect of both holding time $(\Delta t)$ and cooling rate $\left(\gamma_{2}\right)$ on the apparent temperature for $50 \%$ recrystallization, $T_{0.5}^{\prime}$ is given in Fig. 7 for a range of heating rates. $T_{0.5}^{\prime}$ is the perceived recrystallization temperature and approaches $T_{0.5}$ when $\Delta t \rightarrow 0$ and $\gamma_{2} \rightarrow \infty$, or when $\gamma_{1}$ is very low. With reference to Fig. 7, it can be seen that, for low heating rates $\left(<10^{\circ} \mathrm{C} / \mathrm{s}\right)$, both $\Delta t$ and $\gamma_{2}$ have only a small effect on recrystallization, but with increasing heating rate, both $\Delta t$ and $\gamma_{2}$ strongly influence $T_{0.5}^{\prime}$. For example, a high heating rate and a relatively slow cooling rate and/or a small holding time can reduce the apparent recrystallization temperature by over $100^{\circ} \mathrm{C}$. The trends shown in Fig. 7 can be explained in terms of nucleation and growth of grains. With increasing heating rate, the nucleation temperature shifts to higher temperature (Fig. 3(b)) and since the growth rate of recrystallizing grains is highly temperature dependent (Eq. (2)), the influence of both holding time and cooling rate become extremely important at high heating rates.

The model will now be used to illustrate the combined effect of thermocouple response time and cooling rate $\left(\gamma_{2}\right)$ on $T_{0.5}^{\prime}$. If we assume that a small time increment of $\Delta t=0.1 \mathrm{~s}$ passes at $T_{\mathrm{p}}$ before quenching (i.e. instantaneous quenching from $T_{\mathrm{p}}$ does not occur) the effect of cooling rate

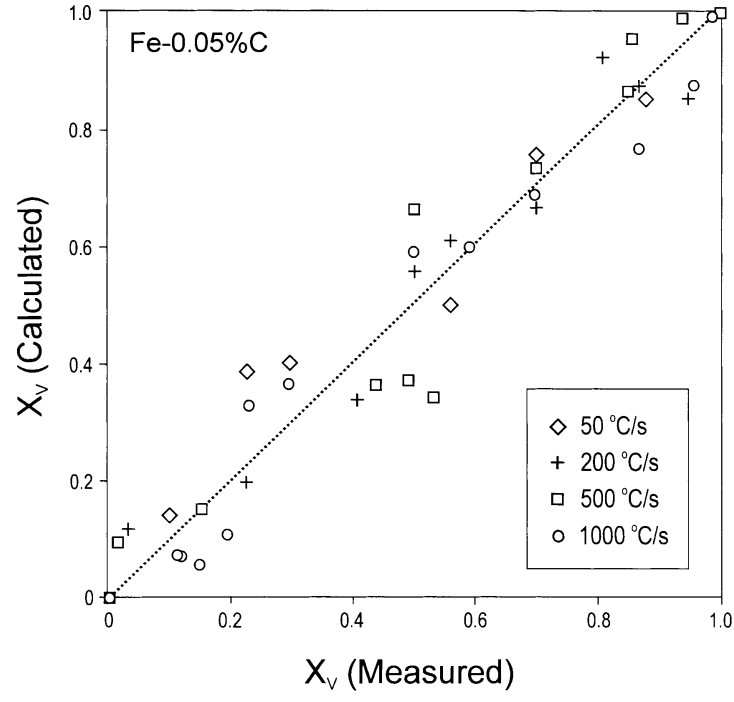

Fig. 6. Relationship between experimentally-observed fraction recrystallized and predictions using Eq. (9) for a $70 \%$ cold rolled low carbon steel (data taken from Ref. 21)).

on $T_{0.5}^{\prime}$ can be calculated, Fig. 8. The dashed curves in Fig. 8 clearly shows the effect of peak temperature overshoot on $T_{0.5}$ (assuming the response time of the thermocouple is $10 \mathrm{~ms}$ ). The uncertainty in determining $T_{\mathrm{p}}$ will increase with heating rate, and for $\gamma_{1}>500^{\circ} \mathrm{C} / \mathrm{s}$, overshooting is manifest as an apparent dip in $T_{0.5}$ (or $T_{0.9}$ etc.). A combination of these factors gives the dashed curves in Fig. 8 and reproduces the so-called ultra rapid softening behaviour ${ }^{3)}$ at high heating rates. The continuous annealing model therefore explains the anomalous behaviour observed in earlier experiments (see e.g. [3]) and demonstrates the importance of careful experimental control needed to generate reproducible recrystallization data at high heating rates.

The present results on a range of steels, together with systematic experiments on overshooting and cooling rate, ${ }^{21)}$ and modelling predictions of the continuous annealing process, indicate that "ultra-rapid softening" may be an artefact of earlier experiments. However, it is pertinent to note that the present work was limited to steels deformed to a single strain ( $70 \%$ reduction) and higher strains may be required to observe ultra rapid softening. ${ }^{28)}$ Further work on specially-prepared steels deformed over a range of strain levels and different deformation modes are needed to clarify the propensity for ultra rapid softening in cold deformed ferrite.

\section{Conclusions}

- For a range of cold rolled steels with carbon levels of $0.003-0.05 \% \mathrm{C}$, increasing heating rate increased the nucleation temperature and temperature range of recrystallization and resulted in a decrease in the recrystallized grain size. There was no evidence to suggest that, for the degree of cold rolling $(70 \%)$ and heating rates examined $\left(50-1000^{\circ} \mathrm{C} / \mathrm{s}\right)$, accelerated softening occurs above a critical heating rate.

- A model based on JMAK transformation kinetics, in conjunction with the rule of additivity for anisothermal phase transformations, has been developed for recrystal- 

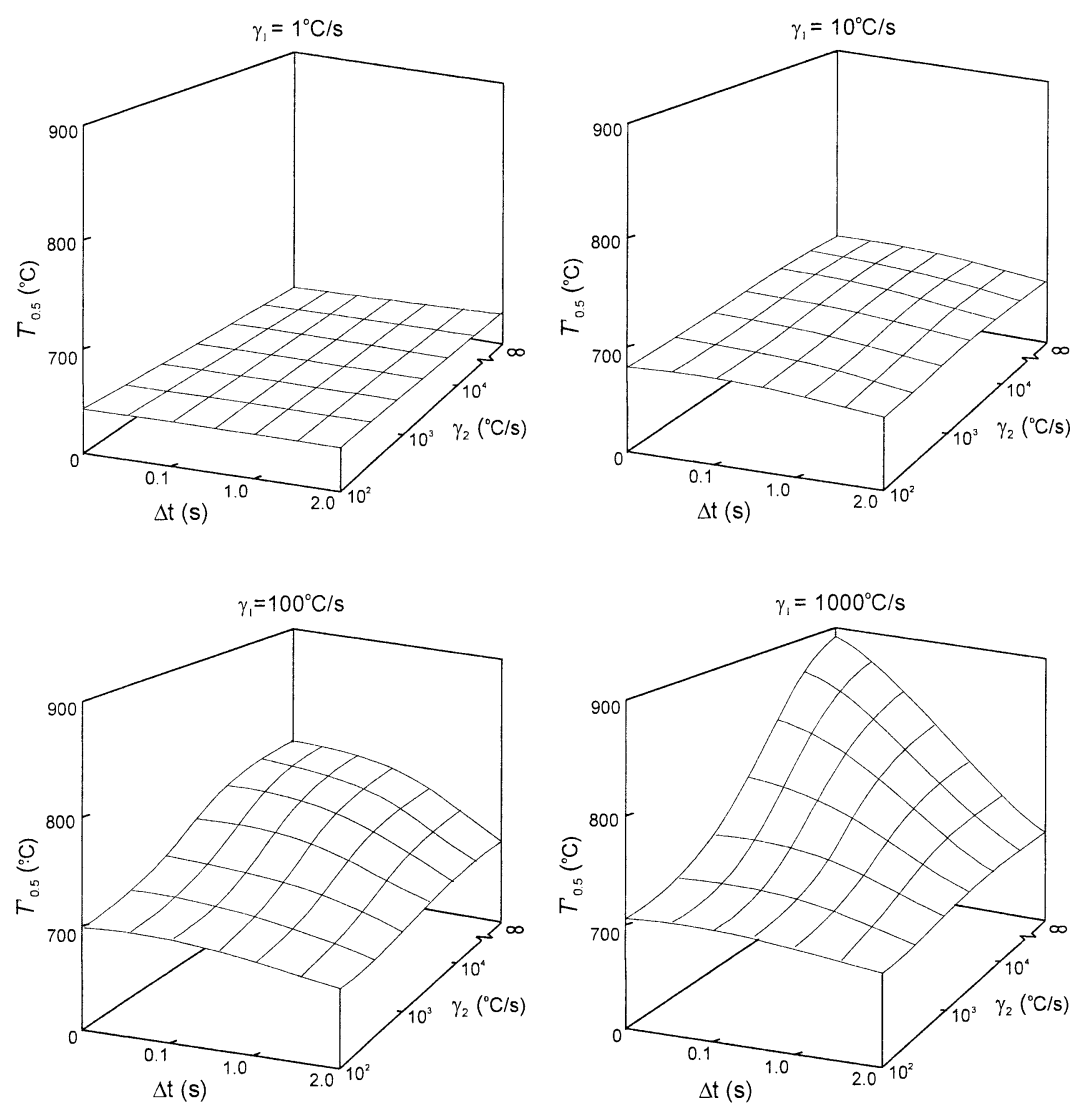

Fig. 7. Model predictions $\{$ Eq. (9) $\}$ showing the strong influence of isothermal holding time $(\Delta t)$ and cooling rate $\left(\gamma_{2}\right)$ on the apparent temperature for $50 \%$ recrystallization $\left(T_{0.5}^{\prime}\right)$ for heating rates in the range 1 to $1000^{\circ} \mathrm{C} / \mathrm{s}$.

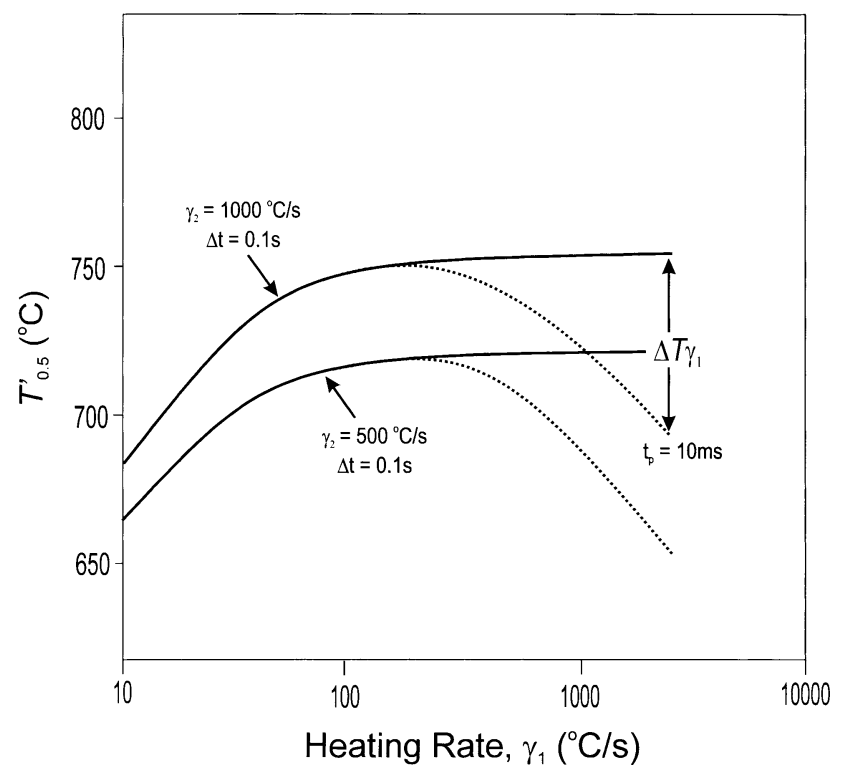

Fig. 8. Model prediction of the effect of cooling rate $\left(\gamma_{2}\right)$ and peak overshoot due to a $10 \mathrm{~ms}$ thermocouple response time, $t_{\mathrm{p}}$ (dashed lines) on $T_{0.5}^{\prime}$ (for a finite holding time of $\Delta t=0.1 \mathrm{~s}) . \Delta T \gamma_{1}$ is the further reduction in $T_{0.5}^{\prime}$ due to peak overshoot.

lization during a multi-stage continuous annealing cycle. This model predicts the progress of recrystallization for a number of anisothermal and isothermal components of a cycle and can be used to follow the progress of recrystallization in complex heat treatments.

- The validity of the continuous annealing model was test- ed using a cold rolled low carbon steel annealed over a wide range of heating rates $\left(50-1000^{\circ} \mathrm{C} / \mathrm{s}\right)$, cooling rates $\left(10-500^{\circ} \mathrm{C} / \mathrm{s}\right)$ and isothermal holding times $(0.05-20 \mathrm{~s})$. It was shown that the model satisfactorily predicts the fraction recrystallized during high-rate continuous annealing where the effect of holding time and cooling rate become significant.

- The model was shown to predict some important trends during continuous annealing, such as the strong effect of holding time and cooling rate on the progress of recrystallization, and illustrates the need for careful control of annealing experiments in order to generate reliable anisothermal recrystallization kinetics data at heating rates above $\sim 10^{\circ} \mathrm{C} / \mathrm{s}$. The experimental results, together with the results of the annealing model, does not support the concept of 'ultra-rapid softening' of previous experiments.

\section{Acknowledgments}

The authors would like to thank BHP Steel-Port Kembla, Australia for providing the steels and Prof. B. A. Parker, Faculty of Engineering, University of Wollongong for provision of laboratory equipment. One of the authors (DM) acknowledges the support of an AUSAID scholarship to allow this work to be carried out at University of Wollongong.

\section{REFERENCES}

1) T. Obara, K. Sakata and T. Irie: Metallurgy of Continuous-Annealed Steel, ed. by B. L Bramfitt and P. L. Mangonon, TMS-AIME, Dallas, Texas, (1982), 83 . 
2) G. W. Hess: New Steel, 11 (1993), 41.

3) M. Atkinson: Mater. Forum, 17 (1993), 181.

4) M. Atkinson: Mater. Sci. Eng. A, 262 (1999), 33.

5) H. Shi: Ph. D Thesis, University of Wollongong, (1990).

6) F. J. Humphreys and M. Hatherly: Recrystallization and Related Annealing Phenomena, Pergamon Press, Oxford, (1995).

7) A. N. Kolmogorov: Izv. Akad. Nauk. USSR. Ser. Mathemat., 1 (1937), 355.

8) W. A. Johnson and R. F. Mehl: Trans. AIME, 135 (1939), 416.

9) M. Avrami: J. Chem. Phys., 7 (1939), 1103; 8 (1940), 212; 9 (1941), 177.

10) T. Furu, K. Marthinsen and E. Nes: Mater. Sci. Technol., 6 (1990), 1093.

11) V. Erukhimovitch and J. Baram: Mater. Sci. Eng. A, 214 (1996), 78.

12) R. A. Vandermeer and B. B. Rath: Metall. Trans. A, 20 (1989), 391.

13) R. A. Vandermeer and B. B. Rath: Metall. Trans. A, 20 (1989), 1933.

14) K. Mukunthan and E. B. Hawbolt: Metall. Trans. A, 27 (1996), 3410.

15) D. J. Srolovitz, G. S. Grest and M. P. Anderson: Acta Metall., 34 (1986), 1833.

16) D. Muljono, M. Ferry and D. P. Dunne: Mater. Sci. Eng. A, 303 (2001), 90 .

17) R. C. Gibson, W. B. R. Moore and R. A. Walker: Mater. Sci. Forum, 102-104 (1992), 373.

18) W. B. Hutchinson and K. Ushioda: Scand. J. Metall., 13 (1984), 269.

19) S. L. Samaitin, I. M. Sukonnik and V. Seetharaman: Metall. Trans A, 27 (1996), 2051.

20) V. Erukhimovitch and J. Baram: Metall. Trans. A, 28 (1997), 2763.

21) D. Muljono: Ph. D Thesis, University of Wollongong, (2001).

22) W. B. Hutchinson: Int. Met. Rev., 29 (1984), 25.

23) R. K. Ray, J. J. Jonas and R. E. Hook: Int. Mater. Rev., 39 (1994) 129.

24) E. Scheil: Arch. Eisenhüttenwes., 12 (1935), 212.

25) J. W. Cahn: Acta Metall., 4 (1956), 572.

26) M. Umemoto, K. Horiuchi and I. Tamura: Trans Iron Steel Inst. Jpn., 23 (1983), 691

27) M. Lusk and H-J Jou: Metall. Trans A, 28 (1997), 287.

28) M. Atkinson: Private communication, (1997).

\section{Appendix A}

The recrystallization model, outlined in Sec. 3.3, is based on JMAK transformation kinetics, in conjunction with the rule of additivity for anisothermal phase transformations. The following general analysis takes into account any number of annealing stages to predict the fraction recrystallized during continuous annealing (see e.g. Fig. 5).

Assuming, for $k$ stages of an annealing cycle, $t_{0}<t_{1} \cdots<$ $t_{k-1}<t_{k}$, Eq. (4) can be written in the general form:

$$
\begin{aligned}
& \int_{t_{0}}^{t_{k}} \frac{d t}{\tau_{X}(T)}=\int_{t_{0}}^{t_{1}} \frac{d t}{\tau}+\int_{t_{1}}^{t_{2}} \frac{d t}{\tau}+\cdots+\int_{t_{k-1}}^{t_{k}} \frac{d t}{\tau}=\sum_{i=1}^{k} \int_{t_{i-1}}^{t_{i}} \frac{d t}{\tau} \\
& =\int_{T_{0}}^{T_{1}} \frac{1}{\tau} \frac{d t}{d T} d T+\int_{t_{1}}^{t_{2}} \frac{d t}{\tau}+\int_{T_{1}}^{T_{2}} \frac{1}{\tau} \frac{d t}{d T} d T+\int_{t_{3}}^{t_{4}} \frac{d t}{\tau}+\cdots \\
& =\sum_{i=1}^{k}\left\{\int_{T_{i-1}}^{T_{i}} \frac{1}{\tau} \frac{d t}{d T} d T+\left(\int \frac{d t}{\tau}\right)_{T_{i}}\right\}
\end{aligned}
$$

then from Eq. (5) we have:

$$
\begin{aligned}
& \int_{T_{0}}^{T_{1}} \frac{1}{\gamma_{1} \tau} d T+\int_{t_{1}}^{t_{2}} \frac{d t}{\tau}+\int_{T_{1}}^{T_{2}} \frac{1}{\gamma_{2} \tau} d T+\int_{t_{3}}^{t_{4}} \frac{d t}{\tau}+\cdots \\
& =\sum_{i=1}^{k}\left\{\int_{T_{i-1}}^{T_{i}} \frac{1}{\gamma_{i} \tau} d T+\left(\int \frac{d t}{\tau}\right)_{T_{i}}\right\}=1
\end{aligned}
$$

Thus, for a multi-stage annealing cycle containing $k$ anisothermal and up to $k$ isothermal stages:

$$
\sum_{i=1}^{k}\left\{\int_{T_{i-1}}^{T_{i}} \frac{1}{\gamma_{i} \tau} d T+\left(\int \frac{d t}{\tau}\right)_{T_{i}}\right\}=1
$$

where $\gamma_{i}$ is the rate of temperature change (positive for heating and negative for cooling) of the $i$ th anisothermal stage of a $k$-stage annealing cycle and $T_{i}$ is the isothermal holding stage (if applicable) following the $i$ th anisothermal stage.

Equation (A-1) can be simplified to:

$$
\phi+\varphi=1
$$

The parameters $\phi$ and $\varphi$ may be combined with Eqs. (1) and (4) to give:

$$
\begin{gathered}
\phi=\frac{1}{\left[\ln \left(\frac{1}{1-X_{\mathrm{v}}}\right)\right]^{1 / n}} \sum_{i=1}^{k} \int_{T_{i-1}}^{T_{i}} \frac{k(T)^{1 / n}}{\gamma_{i}} d T \\
\varphi=\frac{1}{\left[\ln \left(\frac{1}{1-X_{\mathrm{v}}}\right)\right]^{1 / n}} \sum_{i=1}^{k}\left(\int k(T)^{1 / n} d t\right)_{T_{i}}
\end{gathered}
$$

Finally, substituting Eqs. (A-3) and (A-4) into Eq. (A-2) and rearranging terms gives the fraction recrystallized, $X_{\mathrm{v}}$ :

$$
\begin{aligned}
& X_{\mathrm{v}}=1-\exp \left(-\left[\sum _ { i = 1 } ^ { k } \left\{\int_{T_{i-1}}^{T_{i}} \frac{k(T)^{1 / n}}{\gamma_{i}} d t\right.\right.\right. \\
& \left.\left.\left.+\left(\int k(T)^{1 / n} d t\right)_{T_{i}}\right\}\right]^{n}\right)
\end{aligned}
$$

Equation (A-5) takes into account any number $(k)$ of anisothermal components of a given rate $\gamma_{l}$ in an annealing cycle, together with any number of isothermal stages (up to $k$ ). Equation (A-5) reduces to (i) the JMAK equation (Eq. (1)) for $\gamma_{1} \rightarrow \infty$, or for a given heating rate $\left(\gamma_{1}\right)$, when $T=T_{\mathrm{o}}$ (i.e. $T_{\mathrm{o}}$ is reached before recrystallization commences) and (ii) Eq. (1) in Ref. 18) when $\gamma_{2} \rightarrow \infty$ and $\Delta t=0$ (anisothermal annealing). 